\title{
Inhibition of Src Family Kinases and Non-Classical Protein Kinases C Induce a Reeler-Like Malformation of Cortical Plate Development
}

\author{
Yves Jossin, ${ }^{1}$ Masuhara Ogawa, ${ }^{2}$ Christine Metin, ${ }^{3}$ Fadel Tissir, ${ }^{1}$ and André M. Goffinet ${ }^{1}$ \\ ${ }^{1}$ University of Louvain Medical School, Developmental Genetics Unit, GEDE 7382, B1200 Brussels, Belgium, ${ }^{2}$ RIKEN-Brain Sciences Institute, $351-0198$ \\ Saitama, Japan, and 3'U106 Institut National Santé et de la Recherche Médicale, Hôpital Pitié-Salpêtričre, 75651 Paris Cédex 13, France
}

\begin{abstract}
During development, most cortical neurons migrate to the cortical plate (CP) radially. CP development is abnormal in reeler and other mutant mice with defective Reelin signaling. Reelin is secreted by Cajal-Retzius cells and binds to the very low density lipoprotein receptor and apolipoprotein $\mathrm{E}$ receptor type 2 receptors on the surface of $\mathrm{CP}$ cells, inducing tyrosine phosphorylation of the intracellular Dab1 adapter. As with Reelin receptors, the identification of Reelin signaling partners is hampered by genetic redundancy. Using a new in vitro embryonic slice culture system, we demonstrate that chemical inhibitors of Src family kinases and Abl, but not inhibitors of Abl alone, generate a reeler-like malformation and that inhibitors of protein kinases $\mathrm{C}$ induce a malformation of cortical development that is also reminiscent of reeler. Our observations demonstrate a key role for these enzymes in radial migration to the cortical plate, possibly via interference with Reelin signaling.
\end{abstract}

Key words: cortex; development; slice; Reelin; tyrosine kinase; protein kinase C

\section{Introduction}

The cerebral cortex develops according to a finely tuned sequence that includes the proliferation of neuronal precursors in ventricular zones (VZs), followed by migration of postmitotic neurons to form architectonic patterns (Nadarajah and Parnavelas, 2002). The earliest cortical neurons, generated at embryonic day (E) 10.5-11.5 in mice, migrate over short distances and form a loose horizontal network called preplate. Cells that are born later assume a different, radial orientation and settle in a densely packed, laminar structure called the cortical plate $(\mathrm{CP})$. The condensation of the $\mathrm{CP}$ splits the preplate into two cell contingents that settle in the external marginal zone (MZ) and in the subplate (SP), a cell-poor zone between the CP and the intermediate zone of migration. Most neurons migrate toward the $\mathrm{CP}$ radially from telencephalic VZs and are guided by cytoplasmic processes of radial neuroepithelial-glial cells (Rakic, 1972; Rakic and Caviness, 1995; Malatesta et al., 2000; Rakic, 2000, 2002; Noctor et al., 2001). Others originate in ganglionic eminences and reach the $\mathrm{CP}$ by tangential migration (Parnavelas et al., 2002). In the CP, progressively younger neurons migrate radially through previously deposited layers and pile up at superficial levels, resulting in the

Received July 3, 2003; revised Sept. 11, 2003; accepted Sept. 13, 2003.

Y.J. is a fellow from the Fonds de Recherche pour I'Industrie et l'Agriculture. A.M.G. is supported by Grant 3.4533.95 from the Fonds de la Recherche Scientifique et Médicale, Grant 2.4504.01 from the Fonds de la Recherche Fondamentale et Collective, Grants 186 and 248 from the Actions de Recherches Concertées, and by the Fondation Médicale Reine Elisabeth, all from Belgium, as well as by the fifth Framework Program from the European Union (Grant "Concorde" QLG3-CT-2000-00158). We thank L. Bertrand and L. Hue for advice with the use of some inhibitors, Novartis for gift of Gleevec, and Dr. Syu-ichi Hirai for discussion on PKC.

Correspondence should be addressed to André M. Goffinet, University of Louvain Medical School, Developmental Genetics Unit, 73 Avenue Mounier, GEDE 7382, B1200 Brussels, Belgium. E-mail: andre.goffinet@gede.ucl.ac.be. Copyright $\odot 2003$ Society for Neuroscience $\quad$ 0270-6474/03/239953-07\$15.00/0 so-called "inside to outside" gradient of CP maturation (Lambert de Rouvroit and Goffinet, 1998). Among the regulators of cortical development identified in human and rodents (Sun et al., 2002), the Reelin pathway plays a key role. Reelin-deficient (reeler) mice are characterized by three anomalies of early cortical development: (1) the $\mathrm{MZ}$ is diminutive, and the $\mathrm{CP}$ is loose and populated with obliquely oriented neurons; (2) the preplate is not split but instead all of its cells are displaced at subpial levels; and (3) the gradient of cortical maturation is grossly inverted, directed from outside to inside. Reelin is an extracellular glycoprotein secreted in the MZ by Cajal-Retzius cells (D'Arcangelo et al., 1997). It binds to the very low density lipoprotein receptor (VLDLR) and apolipoprotein E receptor type 2 (ApoER2), two members of the lipoprotein receptor family expressed on the surface of CP cells (Hiesberger et al., 1999; Trommsdorff et al., 1999), and this results in tyrosine phosphorylation of the intracellular adapter Dab1 (Howell et al., 1999, 2000; Rice and Curran, 2001; Herrick and Cooper, 2002). Defective Reelin signaling results in Dab1 hypophosphorylation coupled with a drastic upregulation of protein levels (Hiesberger et al., 1999; Howell et al., 1999). The VLDLR and ApoER2 proteins are essentially redundant, and their role as Reelin receptors was identified only after production of double mutant mice (Trommsdorff et al., 1999). Genetic redundancy presumably hampers the identification of other signaling molecules implicated in radial migration and Reelin signaling, such as the kinase(s) responsible for Dab1 phosphorylation, although Fyn and Src (Arnaud et al., 2003; Bock and Herz, 2003) and the phosphatidyl inositide 3 kinase (PI3K) Akt/ PKB pathway (Beffert et al., 2002; Bock et al., 2003) may be involved.

Contrary to tangential migration (Anderson et al., 1997; Par- 
navelas et al., 2000), few in vitro systems have been adapted to the analysis of radial migration (Hemmendinger and Caviness, 1988; Gotz and Bolz, 1992; Anton et al., 1996). A cortical imprint method (Anton et al., 1996) allows estimation of some parameters but does not preserve the structure of the tissue, and slice culture systems described to date are limited by a progressive disorganization of the tissue with blurring of architectonic boundaries. Here we describe an in vitro model of early CP development that allowed us to assess the role of different signaling pathways in radial migration and to identify new putative partners of the Reelin signaling cascade.

\section{Materials and Methods}

Animal procedures were performed according to guidelines for the proper use of laboratory animals and were ratified by the competent institutional Animal Ethics Committees. Normal mice of the BALB/c strain and homozygous reeler mice (Orleans allele) of mixed, predominantly BALB/c background were kept in standard conditions. Pregnancies were dated by detecting vaginal plugs, and the day of the plug was noted E0.5. Pregnant mice were killed by cervical dislocation, and embryos were transferred into cold HBSS under sterile conditions.

For S-phase labeling, bromodeoxyuridine (BrdU) (Sigma, St. Louis, $\mathrm{MO})$ dissolved in $0.9 \% \mathrm{NaCl}$ was injected intraperitoneally $(20 \mu \mathrm{g} / \mathrm{g})$ into the pregnant mouse at defined time points before it was killed. Labeling of neurons at the time of culture was performed by injecting the mouse $1 \mathrm{hr}$ before the beginning of the experiment or by administering a BrdU pulse of $30 \mathrm{~min}$ in the culture medium $(20 \mu \mathrm{g} / \mathrm{ml})$. In some experiments, double labeling was performed by injection of BrdU followed by injection of tritiated thymidine (THY) (Amersham Biosciences, Arlington Heights, Il; TRK758, $5 \mu \mathrm{Ci} / \mathrm{g}$ ) or administration of a $30 \mathrm{~min}$ tritiated thymidine pulse in vitro $(1 \mu \mathrm{Ci} / \mathrm{ml})$.

For vibratome sectioning, the whole fetal brain at E12.5, E13.5, or E14.5 was embedded in 4\% low melting agarose (Promega, Madison, WI) prepared in DMEM-Hank's F12 medium with glutamine, glucose, and HEPES (BioWhittaker, Walkersville, MD) and glued on a vibratome support using cyanoacrylate. Sections ( $300 \mu \mathrm{m}$ thick) were cut in the coronal plane. Care was taken to avoid damage to the pial surface, because this resulted in overmigration of cells in the meninges during culture. In all experiments, a slice was processed for histology immediately after sectioning to verify the developmental status before culture. For culture, sections were laid on collagen-coated polytetrafluoroethylene membranes (Transwell-COL; Costar, catalog \#3494) in 12-well plates, and medium was added to a level covering the section but not more. The culture medium was DMEM-F12 supplemented with B27 (1:50), G5 (1:100), penicillin, and streptomycin [all from BioWhittaker or Invitrogen (Gaithersburg, MD)], but without serum additive. We found it important to culture slices under increased oxygen concentrations (Edgar and Price, 2001; Miyata et al., 2002) and used water-saturated $95 \%$ $\mathrm{O}_{2}-5 \% \mathrm{CO}_{2}$, with a modular incubator chamber (Billups-Rothenberg, Del Mar, CA). Under those conditions, an organized CP consistently appeared after $1 \mathrm{~d}$ in vitro (DIV) and continued to develop after 2 DIV. When the culture was extended to 3 DIV or more, the thickness of the CP did not increase further. Therefore, we concluded that formation of the $\mathrm{CP}$ in vitro was best observed after culturing E13.5 or E14.5 slices for 2 DIV. After culture, slices were fixed in Bouin's fluid for $2 \mathrm{hr}$ before embedding in paraplast and sectioning at $8 \mu \mathrm{m}$ thickness. We found it essential to section each slice serially, because CP development proceeded best in the center $(\sim 100-200 \mu \mathrm{m})$, whereas the external parts $(\sim 100 \mu \mathrm{m})$ almost never contained a dense organized CP, presumably because the tri-dimensional structure of the tissue, particularly the radial glial scaffold, was disturbed in the periphery of the slices during preparation. Sections were stained with hematoxylin eosin to examine their general histology and with anti-BrdU antibodies (Becton Dickinson, Mountain View, CA) to visualize incorporation of BrdU into DNA. Tritiated thymidine was revealed by autoradiography using the Hypercoat LM1 emulsion (Amersham Biosciences). Immunostaining for reelin was performed using antibody G10, and radial glia were revealed with the Rat401 anti-nestin antibody (Calbiochem, La Jolla, CA). Antibodies

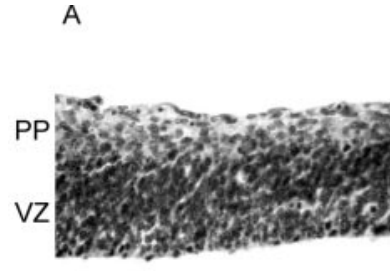

E13.5 (ODIV)

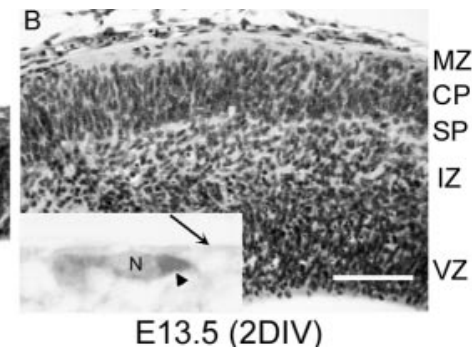

Figure 1. A slice cut at E13.5 and processes just after vibratome sectioning are shown in $A$. The telencephalon is composed of a VZ and the preplate. After 2 DIV $(B)$, a well developed CP appears, bracketed between a cell-poor MZ and the intermediate zone (IZ) of migration. A cell-poor SP is also seen. The MZ contains Reelin-immunoreactive Cajal-Retzius cells (inset).

against myristoylated, alanin-rich C-kinase substrate (MARCKS) and phosphoMARCKS were from Calbiochem, and anti-phosphotyrosine 4 G10 was from Upstate Biotechnology (Lake Placid, NY).

\section{Results}

\section{$\mathrm{CP}$ development in vitro recapitulates development in vivo}

Vibratome slices $(300 \mu \mathrm{m})$ were prepared at E12.5 or E13.5, when the CP is not yet developed (E12.5) or incipient (E13.5), and cultured as described in Materials and Methods. After 2 DIV, a dense CP populated with radial neurons appeared in the external field of the telencephalon, bracketed between an external MZ and an inner subplate layer. The intermediate zone of migration and ventricular zone of neuronal proliferation were clearly visible (Fig. 1). The external MZ contained sparse, large horizontal neurons that resembled Cajal-Retzius cells (Frotscher, 1998) and were Reelin positive (Fig. 1, inset). The relationship between the time of neuron generation and CP development was studied by labeling neuronal cohorts with BrdU or THY, or both, as shown in Figure 2. Injection of pregnant mice with BrdU on the day before they were killed resulted in labeling of a large proportion of CP neurons (Fig. $2 A, B$ ). In contrast, when slices were submitted to a short THY pulse after sectioning, only a few THY-positive neurons were found in the CP after 2 DIV (Fig. 2C), and this number did not increase when the culture was extended farther. When BrdU was added to the culture on the second DIV, no labeled neurons were detected in the CP (Fig. 2D,E), indicating that most cells that settle in the CP complete their last S-phase in vivo, before slice preparation. To assess whether the CP develops in vitro after an inside to outside sequence, double-labeling experiments were performed as follows. Pregnant mice were injected with BrdU on E12.5 and again with THY on the next morning. Slices were prepared $5 \mathrm{hr}$ after THY administration. After 2 DIV, adjacent sections were stained for histological analysis, revealed with anti-BrdU antibodies, and processed for THY autoradiography (Fig. $3 A-C$ ). To estimate the distribution of both cell cohorts, the telencephalic wall was divided into radially superposed compartments (excluding meninges and submeningeal space) as illustrated in Figure $4 A$, and THY- and BrdU-positive cells were counted in each segment. The results (Fig. $4 B$ ) show that BrdU-positive cells were distributed in all layers of the cortical ribbon but were more concentrated in the inner than the outer tier. Conversely, THY-positive neurons were present at every level of the CP but heavily labeled cells were preferentially located in its superficial aspect. Thus a significant proportion of late-migrating, younger neurons were able to pass through the layer formed by the previous cell cohort, showing that CP maturation proceeded from inside to outside. Another feature of normal CP development is the splitting of the preplate by the CP. To 


\section{H.E. staining}

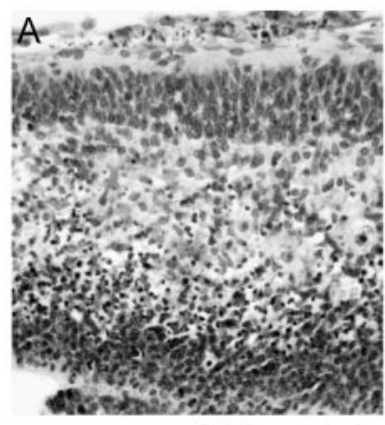

H.E. staining

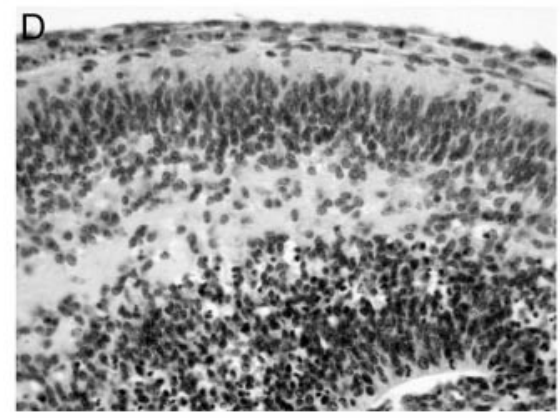

BrdU pulse in vivo $21 \mathrm{~h}$ before slicing

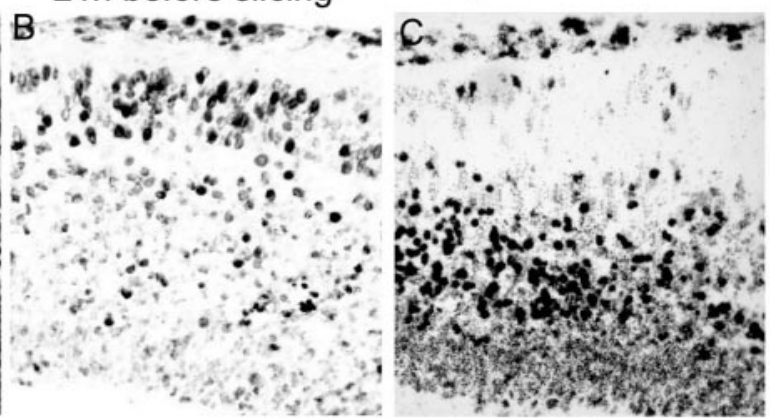

BrdU pulse the second DIV

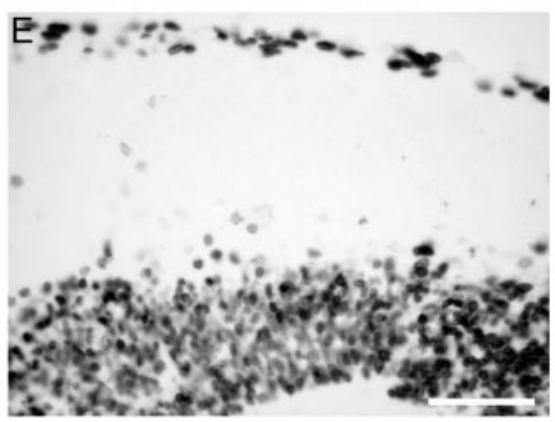

Figure 2. $\quad A-C$, Double-labeling experiment with BrdU administered $21 \mathrm{hr}$ before experiment, followed by a pulse of THY after slice preparation. After 2 DIV, many BrdU-positive but very few THY-positive cells are found in the $C P$, indicating that the cells that migrate to form the CP in vitro are mostly postmitotic at the time of slice preparation. D, E, After BrdU addition to slices after $24 \mathrm{hr}$ in culture, no labeled neurons migrate to the CP $1 \mathrm{~d}$ later, although many labeled cells remain in the intermediate zone.

scribed above, showed that BrdU-positive neurons were dispersed throughout the whole cortical field, whereas THY-labeled cells were located in the deep part of the cortex, in a continuum with migrating cells in the intermediate zone (Fig. $3 E, F$, $4 B$ ). This showed that the reeler CP developed from outside to inside in vitro, as it does in vivo. The morphology of radial glial guides is abnormal in reeler mice (Derer, 1979; Hunter-Schaedle, 1997; Forster et al., 2002). To assess whether this was also seen in reeler slices after culture, sections were stained for the intermediate filament protein nestin, a radial fiber marker. As shown when comparing normal and reeler slices (Fig. 6A,B), reeler radial glial cells were normal in the $\mathrm{VZ}$ and intermediate zone but became quite distorted and formed enlarged and branched fibers in the external tiers of the field, when they crossed the cortical plate and superplate. Altogether, these results indicated that the main features of the reeler phenotype were produced in vitro.

\section{Inhibition of Src family kinases}

Src kinases form a family of at least eight members that are implicated in many cell processes, including cell migration (Blume-Jensen and Hunter, 2001). Like Reelin deficiency, inactivation of Fyn or assess whether this occurred in vitro, BrdU was administered to pregnant mice at E10.5, when preplate neurons are generated, and slices were prepared at E12.5 or E13.5, before CP condensation. After $2 \mathrm{DIV}$, labeled preplate cells were found in the $\mathrm{MZ}$ and subplate, as predicted (Fig. 5A). Thus three main characteristics of early cortical development in vivo, namely radial CP architectonics, inside to outside CP maturation, and PP splitting, were recapitulated in vitro.

\section{In vitro development of the reeler $\mathrm{CP}$}

As mentioned in the Introduction, among the mutations that perturb cortical development, those that affect the Reelin signaling pathway (Reelin, its receptors VLDLR and ApoER2, and the Dab1 adapter) generate a unique malformation: CP neurons assume an oblique orientation and are less densely packed than in the normal CP, the preplate is not split by the developing CP but its neurons settle "en bloc" in the external field where they form a superplate, and the gradient of cortical maturation is grossly inverted (Caviness, 1976, 1982; Lambert de Rouvroit and Goffinet, 1998). To confirm that the formation of the CP observed in vitro mirrors the situation in vivo, experiments were performed using slices from homozygous Reelin-deficient (reeler) embryos. When E13.5 reeler slices were cultured for 2 DIV, a CP developed with morphological features identical to those of the reeler CP in vivo (Fig. 3D). CP neurons differentiated and migrated normally, but their general orientation was oblique rather than radial. The MZ was poorly defined, some cell poor plexiform zones developed within the $\mathrm{CP}$, and the inner border of the $\mathrm{CP}$, the frontier between cortex and subcortex where the subplate normally appears, was barely identified (Caviness, 1982). Double-labeling experiments of reeler slices with BrdU and THY, performed as de-
Src results in upregulation of Dab1 protein levels, suggesting that these kinases play a role in Reelin signaling (Arnaud et al., 2003; Bock and Herz, 2003). To study that question further, we tested whether inhibition of Src family kinases with the well validated neuronal migration and architectonic development in embryonic slices. Experiments performed at the concentrations of 1, 10, and $50 \mu \mathrm{M}$ PP2 and the inactive control compound PP3 (Calbiochem) showed clear effects of PP2 on CP development at $10 \mu \mathrm{M}$, a concentration known to inhibit completely Dab1 phosphorylation in neuronal culture (Arnaud et al., 2003; Bock and Herz, 2003) (our unpublished observations). As shown in Figure $3 G$, in the presence of PP2 but not the inactive PP3 (data not shown), the $\mathrm{CP}$ was loosely organized, with oblique neurons and interposed fiber layers, a phenotype almost identical to that observed in reeler embryos (Caviness, 1976, 1982; Lambert de Rouvroit and Goffinet, 1998). In double-labeling experiments, THYlabeled neurons migrated in the intermediate zone as in normal animals, but they did not cross early-born, BrdU-labeled cortical cells and instead settled at progressively deeper levels, indicating outside to inside CP maturation (Figs. $3 H, I, 4)$. Furthermore, preplate splitting, studied as described above, failed to occur (Fig. $5 C)$.

The nestin-positive radial glial fibers were normal in the VZ and intermediate zone but became somewhat wavy, enlarged, and distorted in the cortical plate and MZ (Fig. $6 C$ ), in a pattern quite evocative of that seen in reeler mice and in slices from reeler embryonic brains.

The activity of PP2 was demonstrated by inhibition of the Reelin-induced tyrosine phosphorylation of Dab1 (Howell et al., 1999) in slices (Fig. 7A). Interestingly, incubation with PP2 reinhibitor PP2 (Hanke et al., 1996) (Calbiochem) would perturb 
sulted in a drastic upregulation of Dab1 protein concentration (Fig. 7A), a biochemical hallmark of defective Reelin signaling (Hiesberger et al., 1999; Arnaud et al., 2003; Bock and Herz, 2003). Thus incubation in the presence of PP2 induced a reeler-like malformation. In addition to Src kinases, PP2 inhibits Abl; however, STI571 (Gleevec), which inhibits Abl but not Src family members, did not have the effects of PP2 (data not shown).

\section{Role of protein kinases $\mathrm{C}$}

Protein kinases C (PKC) are central signaling proteins implicated in a multitude of cellular processes (Newton, 2001). They form a family of at least 10-12 isozymes grouped into three classes, namely conventional PKC $(\alpha, \gamma$, and alternatively spliced $\beta \mathrm{I}$ and $\beta \mathrm{II})$, novel $\mathrm{PKC}(\delta, \epsilon, \eta / 1$, $\theta)$, and atypical $\mathrm{PKC}(\xi, \iota / \lambda)$. In addition, PKC $\mu$ and $\nu$ are considered to form a fourth class or a distinct family named protein kinase D (Newton, 2001). Their prominent role in intracellular signaling prompted us to investigate whether they might be involved in radial migration, possibly by modulating the reelin signal.

Embryonic brain slices were cultured in the presence of the following PKC inhibitors (all from Calbiochem): bisindolylmaleimide 1 (BIM1), Ro318220, and Gö6976. At concentrations known to inhibit many PKC isoforms in cells, BIM1 (5 $\mu \mathrm{M}), \operatorname{Ro} 318220(1 \mu \mathrm{M})$, and Gö6976 $(0.3 \mu \mathrm{M})$ all blocked phosphorylation of MARCKS, a major PKC substrate, demonstrating that they were active in our culture conditions (Fig. 7B). BIM1 and Ro318220 induced a malformation of the developing $\mathrm{CP}$ in slices that was very similar to that obtained with PP2. As shown in Figure 3J, the CP became disorderly, with blunted borders and poorly defined MZs and SPs. Double-labeling experiments with BrdU followed by THY revealed that BrdUpositive cells settled at all levels of the CP, whereas THY-positive elements were deposited at its inner border, in continuity with migrating cells in the intermediate zone, indicating that $\mathrm{CP}$ maturation proceeded from outside to inside (Figs. $3 K, L, 4$ ). BIM1 also inhibited preplate splitting (Fig. 5D). Nestin-positive radial glial fibers were normal in the $\mathrm{VZ}$ and intermediate zone but abnormally branched and thickened in the cortical plate and MZ (Fig. 6D), as in reeler or PP2-treated slices. Thus, like PP2, the large-spectrum PKC inhibitors BIM1 and Ro318220 induced a cortical malformation with many morphological features of the reeler anomaly. Unlike PP2, however, incubation of slices with BIM1 did not induce an upregulation of Dab1 protein levels and did not influence Dab1 phosphorylation (Fig. 7B). Furthermore, analysis of the radial distribution of THY- and BrdU-labeled cells (Figs. 3, 4) showed that more cells were dispersed below the cortical plate than in reeler or PP2-treated slices, indicating that the
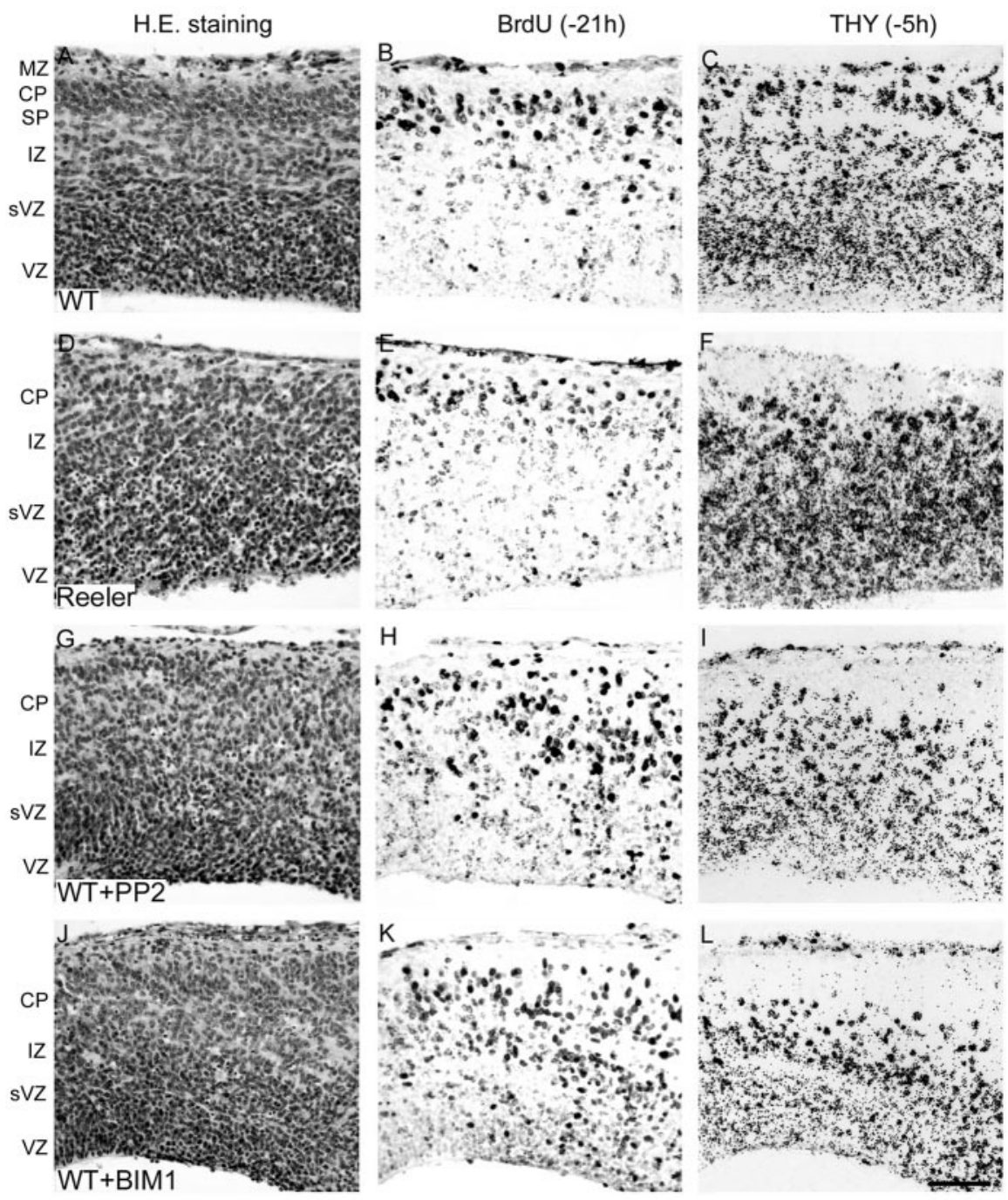

Figure 3. Analysis of CP maturation. Slices prepared at the preplate stage were cultured in vitro for $2 \mathrm{~d}$, after double labeling of the $C P$, whereas THY-positive cells ( $C$ are more concentrated in the external tier. $D-F$, In a similar experiment performed with in the presence of the Src family kinase inhibitor PP2 (10 $\mu \mathrm{M})$, a situation almost identical to reeler is generated, with BrdUpositive cells widely distributed and more concentrated in the outer tier of the (P and THY-positive neurons in the depth. J-L, In normal slices incubated in the presence of the PKC inhibitor BIM1 (5 $\mu \mathrm{M})$, BrdU-positive cells are more concentrated in the outer than in the inner tiers of the $C P$, whereas THY-labeled cells are found atde
the reeler-like condition but may be more severe. Scale bar, $80 \mu \mathrm{m}$.

migration defect induced by PKC inhibitors might be more severe. To define further the PKC family implicated, the compound Gö6976, a canonical inhibitor of classical PKCs but not of the other two families (Martiny-Baron et al., 1993), was tested at various concentrations covering the range of active concentrations in cell cultures. No malformation of CP development was produced, suggesting that the effects observed with BIM1 and Ro318220 are caused by inhibition of the novel or atypical families of calcium-independent PKCs. As an additional argument, BIM1 was active in our assay at $5 \mu \mathrm{M}$, a concentration that blocks all PKC forms, but not at $1 \mu \mathrm{M}$, a concentration that blocks only classical and novel PKCs (Uberall et al., 1997; Mao et al., 2000). This indicated that the effects observed may be caused principally by atypical PKCs. Because several PKC inhibitors are also active 
A

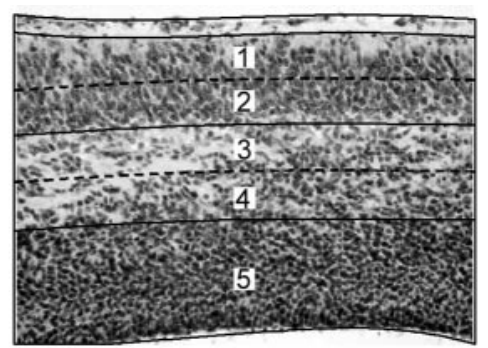

B
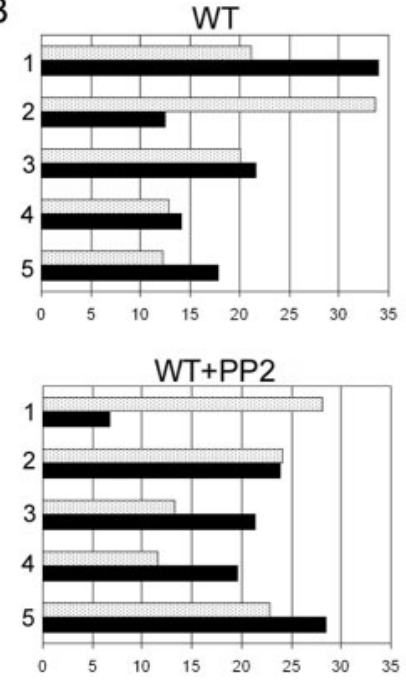

Figure 4. Quantitative analysis of radial maturation. $A$, Schema of the five boxes encompassing the outer (1) and inner (2) tiers of the cortical ribbon (excluding the meninges), the outer (3) and inner (4) tiers of the intermediate zone of migration, and the ventricular-subventricular zones (5) in which BrdU- or THY-positive neurons were counted. B, Between 300 - $400 \mathrm{BrdU}$ and 300-400 THY-labeled cells were counted in four different sections from normal, reeler, PP2-, and BIM1-treated slices, and the proportion in boxes $1-5$ was graphed in gray (BrdU) and black (THY). Boxes 1 and 2 defined in the cortical plate are the most relevant, because the proportion of labeled cells in the deep boxes varied more from experiment to experiment.

against glycogen synthase $3 \beta$ (GSK3 $\beta$ ) (Davies et al., 2000), the GSK3 $\beta$ inhibitor 4-benzyl-2-methyl-1,2,4-thiadiazolidine-3,5dione (TDZD) (Martinez et al., 2002) was tested; at concentrations of 5 and $20 \mu \mathrm{M}$, TDZD did not influence CP development (data not shown).

\section{Discussion}

\section{Radial migration and $\mathrm{CP}$ development in vitro}

Few in vitro systems have been adapted to the analysis of radial migration (Hemmendinger and Caviness, 1988; Gotz and Bolz, 1992; Anton et al., 1996). The main interest of the present culture system is that slices are prepared at the preplate stage, before any condensation of the $\mathrm{CP}$, so that the development of the $\mathrm{CP}$ in vitro proceeds $a b$ initio and is not simply the extension in vitro of a process initiated in vivo. The hallmarks of early normal cortical plate development, namely preplate splitting, the differentiation of the marginal zone and of Cajal-Retzius cells, and the condensation of the $\mathrm{CP}$ with radially organized neurons that settle in the $\mathrm{CP}$ from inside to outside, all occur reproducibly in culture after $2 \mathrm{~d}$. As an additional validation, we showed that early cortical development in slices prepared from reeler embryos mimics development in reeler mice in vivo. CP neurons assume an oblique orientation and are packed less densely than in the normal CP, the preplate is not split by the developing $\mathrm{CP}$ but its neurons settle en bloc in the external field where they form a superplate, and the gradient of cortical maturation is grossly inverted (Caviness,
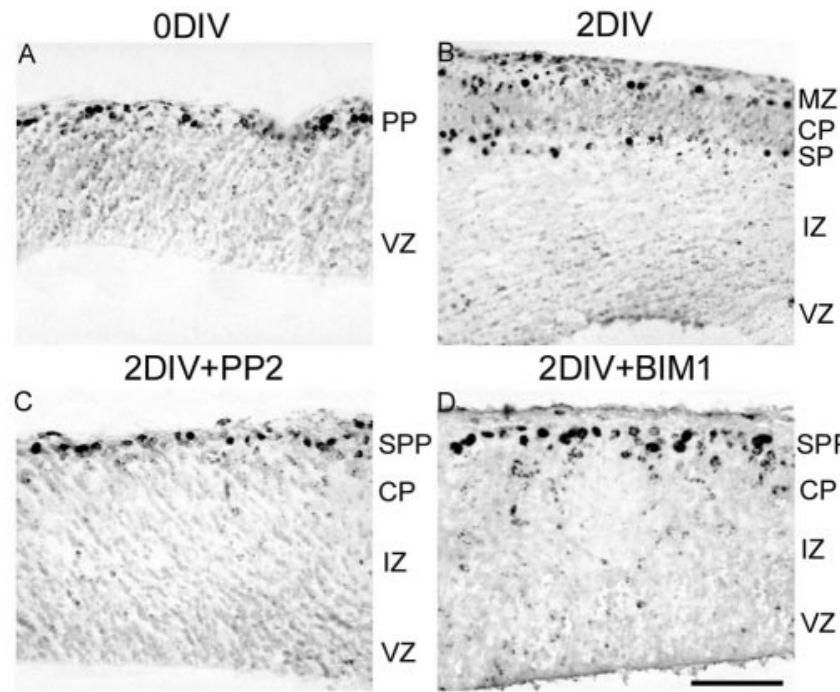

2DIV+BIM1

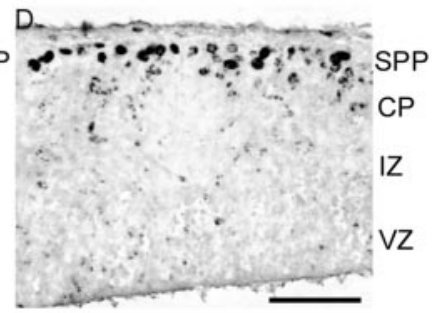

Figure 5. Preplate splitting. Embryos were pulsed with BrdU in vivo at E10.5, and slices were prepared at E13.5 and cultured for $2 \mathrm{DIV}$. At E13.5 $(A)$, before culture, no $\mathrm{CP}$ is yet present, and all labeled neurons are in the preplate. In a normal slice, after $2 \operatorname{DIV}(B)$, the preplate population generated at E10.5 is split into two groups, with cells in the MZ and others in the SP. In contrast, when normal slices are cultured in the presence of PP2 $(10 \mu \mathrm{M})(C)$ or BIM1 $(5 \mu \mathrm{M})(D)$, all preplate elements are found at subpial levels, forming a "super plate" (SPP). In other words, preplate splitting does not occur. Scale bar, $100 \mu \mathrm{m}$.

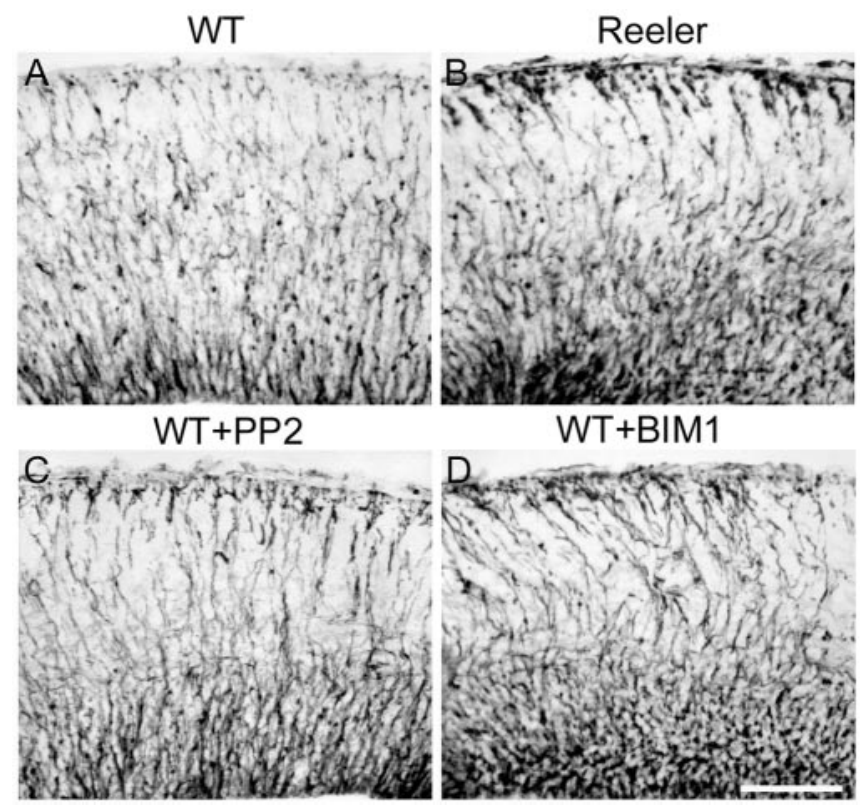

Figure 6. Alterations of the radial glial scaffold, revealed with an anti-nestin antibody. Although normal slices $(A)$ are characterized by a finely organized radial glial scaffold, particularly in its intracortical portion and in the MZ, radial glial fibers in slices from reeler embryos $(B)$ are distorted, with enlarged and branched segments, particularly in the cortical ribbon and in their subpial portion. A rather similar morphology is found when normal slices are treated with PP2 (C) or BIM1 (D): radial glial extensions are wavy and show enlarged portions and increased branching. Scale bar, $80 \mu \mathrm{m}$.

1976, 1982; Lambert de Rouvroit and Goffinet, 1998). Furthermore, the anomalies of radial glial fibers in reeler slices are reminiscent of those described in vivo (Derer, 1979; HunterSchaedle, 1997; Forster et al., 2002).

All technical features of slice preparation and culture mentioned in Materials and Methods are useful, but the most 
A
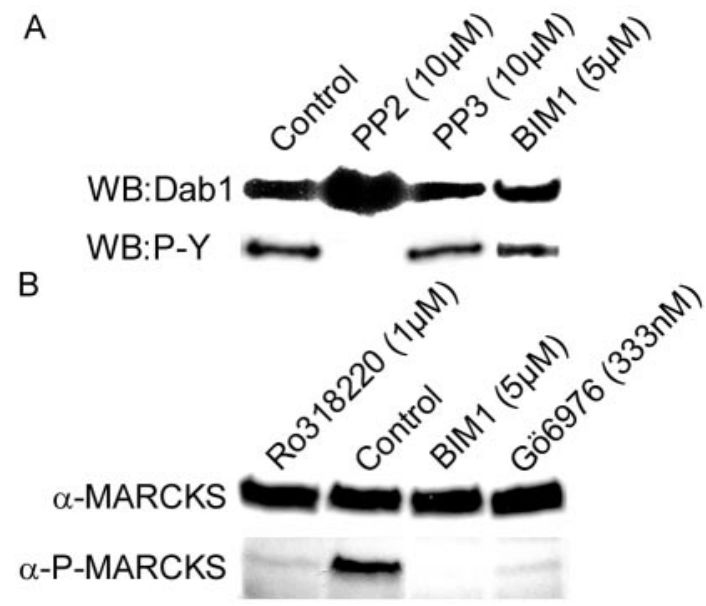

Figure 7. A, PP2 upregulates Dab1 protein concentration but inhibits its phosphorylation in slices, whereas BIM1 does not affect Dab1 levels or phosphorylation. Slices were cultured for 2 DIV in the presence of $10 \mu \mathrm{M}$ PP2 or $5 \mu \mathrm{m} \mathrm{BIM} 1$ or in control conditions [Control and PP3 (10 $\mu \mathrm{M})]$. Slices were homogenized in NP-40 buffer, and Dab1 was immunoprecipitated by a polyclonal antibody (Hiesberger et al., 1999; Howell et al., 1999). Immunoprecipitates were analyzed by PAGE and transferred to polyvinylidene difluoride (PVDF) membranes that were probed with a Dab1 monoclonal antibody (WB:Dab1) and the anti-phosphotyrosine antibody 4G10 (Upstate Biotechnology) (WB:P-Y). B, The PKC inhibitors Ro318220, BIM1, and Gö6976 block MARCKS phosphorylation in the slice culture conditions. After 2 DIV, slices were homogenized and analyzed by PAGE and transferred to PVDF membranes. Western blots were revealed with antibodies (Calbiochem) against the PKC substrate MARCKS ( $\alpha$-MARCKS, bottom panel) and its phosphorylated epitope generated after phosphorylation by PKC ( $\alpha$-P-MARCKS, bottom panel).

significant is the incubation in an oxygen-enriched atmosphere (Miyata et al., 2002), which is found to be critical for cell survival in the depth of the slices. This is particularly important because the $\mathrm{CP}$ develops poorly in the superficial $50-100 \mu \mathrm{m}$ of the slices, whereas a normal CP appears consistently in the $\sim 200 \mu \mathrm{m}$ central zone. We tentatively attribute this phenomenon to distortions of the architecture of the tissue, especially of the radial glial scaffold, during slice preparation. Although this system allows a reproducible development of the CP within 2 DIV, a limitation remains that very few neurons born in vitro migrate to the $\mathrm{CP}$, which is thus populated by neurons that have already completed their last S-phase in vivo, before slice preparation. The reasons for this are unknown and probably many, because some unidentified factor or factors are probably lacking in the culture environment.

\section{Role of Src family kinases and non-classical PKCs}

PP2, an inhibitor of the Src family kinases, produced an anomaly morphologically indistinguishable from reeler in terms of absence of preplate splitting, formation of a loose $\mathrm{CP}$ with an intermediate plexiform layer, outside to inside cortical maturation, and distortion of radial glial fibers. The similarity with reeler is also biochemical, because PP2 induced an upregulation of the Dab1 protein level in addition to inhibition of its phosphorylation. The role of Src family kinases in Reelin signaling was proposed recently by others (Arnaud et al., 2003; Bock and Herz, 2003), but a few observations remained difficult to explain. The addition of Reelin to neurons from mice with combined defects in Fyn, Src, or Yes still triggered Dab1 tyrosine phosphorylation (Arnaud et al., 2003), and the cortical plate that develops in mice with inactivated Fyn, Src, or Yes does not have a reeler-like phenotype. Because PP2 inhibits most Src family members as well as the Abl kinase, our results confirm that the Dab1 kinase(s) belongs to that group and suggest that the observations mentioned above are explained by functional redundancy among the enzymes of the family.

BIM1 and Ro318220, two wide-spectrum PKC inhibitors, induced a malformation of the developing $\mathrm{CP}$ in slices that was reminiscent of that obtained with PP2 and of reeler. Preplate splitting was inhibited, the CP became disorderly, with blunted borders and poorly defined MZs and SPs, and its maturation proceeded from outside to inside. Radial glial fibers were normal in the $\mathrm{VZ}$ and intermediate zone but abnormally branched and thickened in their terminal portion. Unlike PP2, however, PKC inhibitors did not induce an upregulation of Dab1 protein levels nor did they influence Dab1 phosphorylation. Furthermore, analysis of the radial distribution of migrating cells suggested that more cells were dispersed in the intermediate zone than in reeler or PP2-treated slices. These observations indicate that the action of PKC inhibitors occurs in a pathway parallel to reelin or in the reelin pathway itself, or in both, but downstream from the lipoprotein receptor-Dab1 complex. PKCs are implicated in various cellular processes (Newton, 2001). As mentioned above, the family contains at least $10-12$ isozymes grouped into classical $\operatorname{PKC}(\alpha, \gamma$ and alternatively spliced $\beta \mathrm{I}$ and $\beta \mathrm{II})$, novel PKC $(\delta, \epsilon$, $\eta / l, \theta)$, and atypical PKC $(\xi, \iota / \lambda)$. Gö6976, an inhibitor of classical PKCs but not of the other families (Martiny-Baron et al., 1993), was active biochemically but failed to induce any disturbance of cortical development, indicating that non-classical PKCs are involved. Furthermore, the observation that BIM1, which blocks classical and novel PKCs at low concentrations, interfered with CP development only at a high concentration suggests that atypical PKCs are the best candidates. Interestingly, aPKCs have been recently implicated in cell migration and polarity in other assays (Etienne-Manneville and Hall, 2003); however, no PKC mutations in mice, including inactivation of aPKCs, generate a reelerlike phenotype (Dempsey et al., 2000; Leitges et al., 2001; Suzuki et al., 2003), indicating that, as in the case of Src family kinases, redundancy complicates genetic analyses.

In conclusion, we validate a simple in vitro system in which all key features of early cortical development proceed as in vivo, namely the appearance of a radially organized CP, preplate splitting, and inside-outside CP maturation. Using this model, we show that inhibition of Src family kinases, but not of Abl alone, and of PKC of the non-classical families induces a developmental malformation reminiscent of that observed in mice with defective Reelin signaling. Interestingly, most of the genes of these kinase families have been inactivated in mice, but no single or even double mutation generates the overt neuronal migration phenotype produced in vitro, suggesting genetic redundancy. Our system provides a relatively simple way to study some molecular mechanisms of cortical development and to screen for potential deleterious effects of pharmaceuticals or xenobiotics. It suggests further that a "chemical genomics" (Peterson and Mitchison, 2002) approach of cortical development could be considered.

\section{References}

Anderson SA, Eisenstat DD, Shi L, Rubenstein JL (1997) Interneuron migration from basal forebrain to neocortex: dependence on Dlx genes. Science 278:474-476.

Anton ES, Cameron RS, Rakic P (1996) Role of neuron-glial junctional domain proteins in the maintenance and termination of neuronal migration across the embryonic cerebral wall. J Neurosci 16:2283-2293.

Arnaud L, Ballif BA, Forster E, Cooper JA (2003) Fyn tyrosine kinase is a critical regulator of disabled-1 during brain development. Curr Biol 13:9-17.

Beffert U, Morfini G, Bock HH, Reyna H, Brady ST, Herz J (2002) Reelinmediated signaling locally regulates protein kinase B/Akt and glycogen synthase kinase 3beta. J Biol Chem 277:49958-49964. 
Blume-Jensen P, Hunter T (2001) Oncogenic kinase signaling. Nature 411:355-365.

Bock HH, Herz J (2003) Reelin activates SRC family tyrosine kinases in neurons. Curr Biol 13:18-26.

Bock HH, Jossin Y, Liu P, Forster E, May P, Goffinet AM, Herz J (2003) PI3-kinase interacts with the adaptor protein Dab1 in response to Reelin signaling and is required for normal cortical lamination. J Biol Chem 278:38772-38779.

Caviness Jr VS (1976) Patterns of cell and fiber distribution in the neocortex of the reeler mutant mouse. J Comp Neurol 170:435-447.

Caviness Jr VS (1982) Neocortical histogenesis in normal and reeler mice: a developmental study based upon $\left[{ }^{3} \mathrm{H}\right]$ thymidine autoradiography. Brain Res 256:293-302.

D’Arcangelo G, Nakajima K, Miyata T, Ogawa M, Mikoshiba K, Curran T (1997) Reelin is a secreted glycoprotein recognized by the CR-50 monoclonal antibody. J Neurosci 17:23-31.

Davies SP, Reddy H, Caivano M, Cohen P (2000) Specificity and mechanism of action of some commonly used protein kinase inhibitors. Biochem J 351:95-105.

Dempsey EC, Newton AC, Mochly-Rosen D, Fields AP, Reyland ME, Insel PA, Messing RO (2000) Protein kinase C isozymes and the regulation of diverse cell responses. Am J Physiol Lung Cell Mol Physiol 279:L429-L438.

Derer P (1979) Evidence for the occurrence of early modifications in the "glia limitans" layer of the neocortex of the reeler mutant mouse. Neurosci Lett 13:195-202.

Edgar JM, Price DJ (2001) Radial migration in the cerebral cortex is enhanced by signals from thalamus. Eur J Neurosci 13:1745-1754.

Etienne-Manneville S, Hall A (2003) Cell polarity: Par6, aPKC and cytoskeletal crosstalk. Curr Opin Cell Biol 15:67-72.

Forster E, Tielsch A, Saum B, Weiss KH, Johanssen C, Graus-Porta D, Muller U, Frotscher M (2002) Reelin, Disabled 1, and beta 1 integrins are required for the formation of the radial glial scaffold in the hippocampus. Proc Natl Acad Sci USA 99:13178-13183.

Frotscher M (1998) Cajal-Retzius cells, Reelin, and the formation of layers. Curr Opin Neurobiol 8:570-575.

Gotz M, Bolz J (1992) Formation and preservation of cortical layers in slice cultures. J Neurobiol 23:783-802.

Hanke JH, Gardner JP, Dow RL, Changelian PS, Brissette WH, Weringer EJ, Pollok BA, Connelly PA (1996) Discovery of a novel, potent, and Src family-selective tyrosine kinase inhibitor. Study of Lck- and FynTdependent $\mathrm{T}$ cell activation. J Biol Chem 271:695-701.

Hemmendinger LM, Caviness VS Jr (1988) Cellular migration in developing cerebral wall explants in vitro. Brain Res 466:291-295.

Herrick TM, Cooper JA (2002) A hypomorphic allele of dab1 reveals regional differences in reelin-Dabl signaling during brain development. Development 129:787-796.

Hiesberger T, Trommsdorff M, Howell BW, Goffinet A, Mumby MC, Cooper JA, Herz J (1999) Direct binding of Reelin to VLDL receptor and ApoE receptor 2 induces tyrosine phosphorylation of disabled-1 and modulates tau phosphorylation. Neuron 24:481-489.

Howell BW, Herrick TM, Cooper JA (1999) Reelin-induced tryosine phosphorylation of disabled 1 during neuronal positioning. Genes Dev 13:643-648.

Howell BW, Herrick TM, Hildebrand JD, Zhang Y, Cooper JA (2000) Dab1 tyrosine phosphorylation sites relay positional signals during mouse brain development. Curr Biol 10:877-885.

Hunter-Schaedle KE (1997) Radial glial cell development and transformation are disturbed in reeler forebrain. J Neurobiol 33:459-472.

Lambert de Rouvroit C, Goffinet AM (1998) The reeler mouse as a model of brain development. Adv Anat Embryol Cell Biol 150:1-106.
Leitges M, Mayr M, Braun U, Mayr U, Li C, Pfister G, Ghaffari-Tabrizi N, Baier G, Hu Y, Xu Q (2001) Exacerbated vein graft arteriosclerosis in protein kinase Cdelta-null mice. J Clin Invest 108:1505-1512.

Malatesta P, Hartfuss E, Gotz M (2000) Isolation of radial glial cells by fluorescent-activated cell sorting reveals a neuronal lineage. Development 127:5253-5263.

Mao M, Fang X, Lu Y, Lapushin R, Bast Jr RC, Mills GB (2000) Inhibition of growth-factor-induced phosphorylation and activation of protein kinase B/Akt by atypical protein kinase C in breast cancer cells. Biochem J 352:475-482.

Martinez A, Alonso M, Castro A, Perez C, Moreno FJ (2002) First non-ATP competitive glycogen synthase kinase 3 beta (GSK-3beta) inhibitors: thiadiazolidinones (TDZD) as potential drugs for the treatment of Alzheimer's disease. J Med Chem 45:1292-1299.

Martiny-Baron G, Kazanietz MG, Mischak H, Blumberg PM, Kochs G, Hug H, Marme D, Schachtele C (1993) Selective inhibition of protein kinase C isozymes by the indolocarbazole Go 6976. J Biol Chem 268:9194-9197.

Miyata T, Kawaguchi A, Saito K, Kuramochi H, Ogawa M (2002) Visualization of cell cycling by an improvement in slice culture methods. J Neurosci Res 69:861-868.

Nadarajah B, Parnavelas JG (2002) Modes of neuronal migration in the developing cerebral cortex. Nat Rev Neurosci 3:423-432.

Newton AC (2001) Protein kinase C: structural and spatial regulation by phosphorylation, cofactors, and macromolecular interactions. Chem Rev 101:2353-2364.

Noctor SC, Flint AC, Weissman TA, Dammerman RS, Kriegstein AR (2001) Neurons derived from radial glial cells establish radial units in neocortex. Nature 409:714-720.

Parnavelas JG, Anderson SA, Lavdas AA, Grigoriou M, Pachnis V, Rubenstein JL (2000) The contribution of the ganglionic eminence to the neuronal cell types of the cerebral cortex. Novartis Found Symp 228:129-147.

Parnavelas JG, Alifragis P, Nadarajah B (2002) The origin and migration of cortical neurons. Prog Brain Res 136:73-80.

Peterson JR, Mitchison TJ (2002) Small molecules, big impact. A history of chemical inhibitors and the cytoskeleton. Chem Biol 9:1275-1285.

Rakic P (1972) Mode of cell migration to the superficial layers of fetal monkey neocortex. J Comp Neurol 145:61-83.

Rakic P (2000) Molecular and cellular mechanisms of neuronal migration: relevance to cortical epilepsies. Adv Neurol 84:1-14.

Rakic P (2002) Evolving concepts of cortical radial and areal specification. Prog Brain Res 136:265-280.

Rakic P, Caviness Jr VS (1995) Cortical development: view from neurological mutants two decades later. Neuron 14:1101-1104.

Rice DS, Curran T (2001) Role of the reelin signaling pathway in central nervous system development. Annu Rev Neurosci 24:1005-1039.

Sun XZ, Takahashi S, Cui C, Zhang R, Sakata-Haga H, Sawada K, Fukui Y (2002) Normal and abnormal neuronal migration in the developing cerebral cortex. J Med Invest 49:97-110.

Suzuki A, Akimoto K, Ohno S (2003) Protein kinase C lambda/iota: A PKC isotype essential for the development of multicellular organisms. J Biochem 133:9-16.

Trommsdorff M, Gotthardt M, Hiesberger T, Shelton J, Stockinger W, Nimpf J, Hammer RE, Richardson JA, Herz J (1999) Reeler/Disabled-like disruption of neuronal migration in knockout mice lacking the VLDL receptor and ApoE receptor 2. Cell 97:689-701.

Uberall F, Giselbrecht S, Hellbert K, Fresser F, Bauer B, Gschwendt M, Grunicke HH, Baier G (1997) Conventional PKC-alpha, novel PKC-epsilon and PKC-theta, but not atypical PKC-lambda are MARCKS kinases in intact NIH 3T3 fibroblasts. J Biol Chem 272:4072-4078. 